\title{
Use of Uric Acid-Lowering Agents Limits Experimental Cyclosporine Nephropathy
}

\author{
Fernanda Cristina Mazali ${ }^{a}$ Richard J. Johnson ${ }^{b}$ Marilda Mazzalia \\ aDivision of Nephrology, School of Medical Sciences, State University of Campinas, UNICAMP, Campinas, Brazil; \\ ${ }^{b}$ Division of Renal Diseases and Hypertension, Department of Medicine, University of Colorado, Denver, Colo., USA
}

\section{Key Words}

Cyclosporine $\cdot$ Uric acid $\cdot$ Arteriolar hyalinosis ·

Tubulointerstitial fibrosis

\begin{abstract}
Background: Hyperuricemia frequently complicates cyclosporine (CsA) therapy. Previous studies have shown that hyperuricemia exacerbates interstitial and vascular lesions in the cyclosporine model. We tested the hypothesis that normalization of uric acid could prevent the development of cyclosporine toxicity. Methods: CsA nephropathy was induced by administering CsA ( $15 \mathrm{mg} / \mathrm{kg} /$ day) for 7 weeks to rats on a low salt diet (CsA group). The effect of preventing hyperuricemia was determined by concomitant treatment with a xanthine oxidase inhibitor, allopurinol (CSAALP), or with a uricosuric, benzbromarone (CSABENZ), in drinking water. Control groups included vehicle-treated rats. Results: CsAtreated rats developed mild hyperuricemia with arteriolar hyalinosis, tubular atrophy, striped interstitial fibrosis, increased cell proliferation and decreased VEGF expression. Treatment with allopurinol or benzbromarone limited renal disease, with reduced interstitial fibrosis, cell proliferation, macrophage infiltration, osteopontin expression and arteriolar hyalinosis, in association with restoration of VEGF expression. Both drugs provided comparable protection. Conclusions: An increase in uric acid exacerbates CsA nephropathy in the rat. Concomitant treatment with allopurinol or
\end{abstract}

benzbromarone reduced the severity of renal disease. The similar protection observed with both drugs suggests that the effect is associated more with lowering uric acid levels than the antioxidant effect of allopurinol.

$$
\text { Copyright } \odot 2011 \text { S. Karger AG, Basel }
$$

\section{Introduction}

Cyclosporine (CsA) was introduced in the 1980s as an immunosuppressive agent, and quickly became a firstline treatment in organ transplantation as well as in other immunologically mediated diseases [1]. CsA has numerous side effects, of which nephrotoxicity $[2,3]$ and hyperuricemia [4] are the most important. As many as $50 \%$ of patients taking CsA become hyperuricemic [5-7] and approximately $10 \%$ develop gout [8]. The hyperuricemia from CsA results from a decrease in the glomerular filtration rate [9] as well as an increase in net tubular urate reabsorption $[10,11]$. The most important complication of CsA is nephrotoxicity, which is characterized by striped interstitial fibrosis, tubular atrophy, and arteriolar hyalinosis $[1,12,13]$. The pathogenesis of CsA nephropathy is multifactorial but likely involves afferent arteriolar vasoconstriction with activation of the renin angiotensin pathway and inhibition of intrarenal nitric oxide production [14-16].

\section{KARGER}

(C) 2011 S. Karger AG, Basel

Fax +4161306 1234 E-Mail karger@karger.ch www.karger.com www.karger.com/nee
Marilda Mazzali, MD, Nephrology Lab I/Division of Nephrology

Department of Medicine - School of Medical Sciences (DCM/FCM UNICAMP)

State University of Campinas, Rua Tessália Vieira de Camargo, 126

Campinas, SP 13083-970 (Brazil)

Tel. +55 193521 8204, E-Mail marildamazzali@gmail.com 
Previous studies have shown that hyperuricemia exacerbates cyclosporine nephrotoxicity [17] and other models of renal disease [18] by an ischemic mechanism that leads to the development of afferent arteriolar vasculopathy without uric acid crystals [19]. The mechanism by which uric acid is thought to induce renal injury is thought to be mediated by endothelial dysfunction with a reduction in endothelial nitric oxide bioavailability [20] and the activation of the renin-angiotensin system [19] leading to renal vasoconstriction [21] and due to direct effects of uric acid on vascular smooth muscle cells [22] and endothelial cells [23].

We therefore decided to test the hypothesis that normalization of uric acid levels might protect against cyclosporine nephropathy.

\section{Animals and Methods}

Animals

Studies were conducted in 23 adult male Sprague-Dawley rats (CEMIB UNICAMP, Campinas-SP, Brazil) weighing 200-250 g. All rats were fed a low salt soy-based diet $(0.1 \% \mathrm{NaCl}$, $)$ with water ad libitum. The use of low salt diet has been shown to accelerate the development of CsA nephropathy $[13,24]$. After 1 week on a low salt diet, weight-matched rats were randomly divided into four groups: (1) vehicle - these rats received a daily SC injection of olive oil (same volume as CsA group), for 7 weeks $(n=5)$; (2) CsA - these rats received a daily SC injection of cyclosporine 15 $\mathrm{mg} / \mathrm{kg}$, for 7 weeks $(\mathrm{n}=6)$; (3) CsA plus allopurinol (CsAALP) these rats received a daily injection of cyclosporine $15 \mathrm{mg} / \mathrm{kg}$, and allopurinol in drinking water, and (4) CsA plus benzbromarone (CsABENZ) - these rats received a daily injection of cyclosporine $15 \mathrm{mg} / \mathrm{kg}$, and benzbromarone diluted in drinking water. Study protocol was approved by local Ethics Committee for Experimental Research (CEEA/UNICAMP).

\section{Experimental Design}

At the end of 7 weeks, rats were placed in individual metabolic cages for 16-hour urine collection. The next day, rats were anesthetized with xylazine and ketamine; serum was collected for creatinine and uric acid measurements, and both kidneys were obtained for histological evaluation. Biopsies were fixed in $10 \%$ formalin or methyl Carnoy's.

\section{Functional Data}

Serum creatinine was measured by a standard picric acid method. Serum uric acid was measured by uricase method (CELM, Brazil), according to the manufacturer's instructions.

Drugs

Cyclosporine (Novartis) was diluted in olive oil to a final concentration of $5 \mathrm{mg} / \mathrm{ml}$ and injected SC daily in a dose of $15 \mathrm{mg} / \mathrm{kg}$ of body weight.

Allopurinol $300 \mathrm{mg}$ tablets were diluted in drinking water at a final concentration of $15 \mathrm{mg} / \mathrm{dl}$.

Uric Acid-Lowering Agents Limit

Experimental Cyclosporine Nephropathy
Benzbromarone (Narcaricina $100 \mathrm{mg}$ ) tablets were diluted in drinking water at a final concentration of $15 \mathrm{mg} / \mathrm{dl}$.

Renal Morphology and Immunohistochemistry

Methyl Carnoy's fixed tissue was processed and paraffin embedded, and 4- $\mu \mathrm{m}$ sections were stained with the periodic acid Schiff reagent (PAS) and hematoxylin-eosin. Slides were also stained with Sirius red for quantification of collagen deposition.

Methyl-Carnoy's fixed tissue sections were analyzed by indirect immunoperoxidase with primary antibodies against osteopontin (OPN; mouse monoclonal anti-rat osteopontin/OPN-AKM2A1, Santa Cruz Biotechnology, Santa Cruz, Calif., USA, 1:250, overnight at $4^{\circ} \mathrm{C}$ ), monocytes and macrophages (ED-1 mouse anti-rat CD68-MCA341A/Serotec Immunological Excellence ${ }^{\circledR}$, $1: 100$, overnight at $4^{\circ} \mathrm{C}$ ), cell proliferation (monoclonal anti-proliferating cell nuclear antigen - PCNA/Sigma ${ }^{\circledR}, 1: 1,000$, overnight at $4^{\circ} \mathrm{C}$ ) and VEGF (mouse monoclonal anti-rat VEGF, C-1: sc7269 , Santa Cruz, 1:400, overnight at $4^{\circ} \mathrm{C}$ ), followed by a biotinylated secondary antibody, ABC system (Universal SuperABC kit, Erviegas ${ }^{\circledR}$ ). Diaminobenzidine (Liquid DAB Substrate, Chromogen System Code K3466, DAKO Cytomation ${ }^{\circledR}$ ) was used as a chromogen, and slides were counterstained with hematoxylin (OPN, ED-1 and VEGF) or PAS without hematoxylin (PCNA staining).

\section{Quantification of Morphological Data}

All the histological analysis was performed in a blinded fashion. The tubular expression of OPN, which is a sensitive marker of tubulointerstitial injury [25], was calculated as the percentage (\%) of renal cortex occupied by OPN-positive tubules, using computer-assisted image analysis software (KS 300) and digitized images. The percentage of area occupied by OPN-positive tubules per $4 \mathrm{~mm}^{2}$ field at $\times 200$ magnification was measured, and the mean percent area calculated for each biopsy.

The mean number of cortical interstitial macrophages (ED-1+ cells $/ \mathrm{mm}^{2}$ ) in each biopsy was measured by counting the total number of positive cells in 20 sequentially selected $0.25 \mathrm{~mm}^{2}$ grids at $\times 200$ magnification. The number of macrophages per glomerular cross-section (utilizing a minimum of 100 glomeruli per biopsy) was also determined.

The mean number of proliferating cells (PCNA+ cells $/ \mathrm{mm}^{2}$ ) in each biopsy was calculated by counting the total number of positive cells in selected $0.25 \mathrm{~mm}^{2}$ grids at $\times 200$ magnification. The number of positive cells in proximal or distal tubules, interstitium and glomeruli was quantified. Proximal and distal tubules were differentiated according to the presence of brush border by PAS counterstaining.

Interstitial fibrosis was quantified in biopsies stained with Sirius red by color image analysis (KS300), by counting the percentage (\%) of injured areas per field of cortex. The percent area was measured, and mean percent area calculated for each biopsy. Arteriolar hyalinosis was determined by counting the number of afferent arterioles with hyalinosis in the total number of glomeruli showing afferent arterioles on PAS-stained tissue.

VEGF was measured as the percentage (\%) of renal cortex occupied by VEGF-positive tubules, using computer-assisted image analysis software (KS 300) and digitized images. The percentage of area occupied by VEGF-positive tubules per $4 \mathrm{~mm}^{2}$ field at $\times 200$ was measured, and the mean percent area calculated for each biopsy. 
Table 1. Functional data from study groups

\begin{tabular}{lcccc}
\hline & Control & CsA & CsAALP & CsABENZ \\
\hline Animals & 5 & 6 & 6 & 6 \\
Baseline body weight, g & $240.3 \pm 43.8$ & $222.4 \pm 33.2$ & $241.5 \pm 29.6$ & $233.3 \pm 32.7$ \\
Body weight at 7 weeks, g & $222.2 \pm 20.2$ & $169.0 \pm 16.7^{\mathrm{a}, \mathrm{c}, \mathrm{d}}$ & $221.0 \pm 20.6^{\mathrm{b}}$ & $204.2 \pm 21.4^{\mathrm{a}-\mathrm{c}}$ \\
Baseline serum creatinine, $\mathrm{mg} / \mathrm{dl}$ & $0.4 \pm 0.2$ & $0.4 \pm 0.1$ & $0.4 \pm 0.2$ & $0.4 \pm 0.2$ \\
Serum creatinine at 7 weeks, mg/dl & $0.5 \pm 0.2$ & $1.0 \pm 0.2^{\mathrm{a}, \mathrm{c}, \mathrm{d}}$ & $0.6 \pm 0.3^{\mathrm{b}}$ & $0.5 \pm 0.2^{\mathrm{b}}$ \\
Baseline serum uric acid, $\mathrm{mg} / \mathrm{dl}$ & $1.8 \pm 1.0$ & $1.6 \pm 0.3$ & $1.7 \pm 0.5$ & $1.63 \pm 0.07$ \\
Serum uric acid at 7 weeks, $\mathrm{mg} / \mathrm{dl}$ & $1.9 \pm 0.5$ & $4.4 \pm 0.5^{\mathrm{a}, \mathrm{c}, \mathrm{d}}$ & $2.0 \pm 1.4^{\mathrm{b}}$ & $1.9 \pm 0.5^{\mathrm{b}}$ \\
\hline
\end{tabular}

${ }^{\mathrm{a}} \mathrm{p}<0.05$ vs. VEH; ${ }^{\mathrm{b}} \mathrm{p}<0.05$ vs. CsA; ${ }^{\mathrm{c}} \mathrm{p}<0.05$ vs. CsAALP; ${ }^{\mathrm{d}} \mathrm{p}<0.05$ vs. CsABENZ.

Statistical Analysis

All values are expressed as mean \pm SE, unless otherwise stated. The differences between groups were compared by analysis of variance with the Bonferroni correction, and significance defined as $\mathrm{p}<0.05$.

\section{Results}

The low salt soy diet was well tolerated. CsA-treated rats gained less weight than the vehicle or CsAALP or CsABENZ, but the weight gain was similar in CsAALP, CsABENZ and control groups (table 1). All animals remained normotensive during all the study period. Cyclosporine trough levels were stable and comparable in all treated groups during the study period (mean trough level 2,000 ng/dl).

After 7 weeks of treatment, serum uric acid in control rats on a low salt diet was $1.8 \pm 1.0 \mathrm{mg} / \mathrm{dl}$ at week 7 (table 1). In rats receiving CsA alone, the uric acid levels were increased 1.5- to 2-fold. As expected, both allopurinol and benzbromarone maintained serum uric acid at control levels (table 1).

Renal function was evaluated by measuring serum creatinine, and was reduced in CsA group compared to control animals (table 1). Both CsAALP and CsABENZ groups maintained renal function at normal levels at the end of 7 weeks' treatment.

\section{Histological Analysis}

Tubulointerstitial and Microvascular Changes

Rats treated with CsA for 7 weeks displayed classic histological findings of chronic CsA nephropathy, with arteriolar hyalinosis, tubular dilatation, and atrophy in a striped pattern. Both allopurinol and benzbromarone treatment resulted in significantly less renal injury, including a reduction in both the frequency of arterio- lar hyalinosis and the severity of interstitial fibrosis (table 2; fig. 1).

\section{Collagen Deposition}

In vehicle-treated rats, collagen was minimally present in renal cortex, with slight accumulation around interlobular arteries and veins. In rats on CsA, collagen was increased in both the cortex and subcapsular area, and displayed a striped interstitial pattern similar to that observed by routine light microscopy. Treatment with allopurinol or benzbromarone reduced the collagen deposition in this model (fig. $1 \mathrm{~b}-\mathrm{e}$ ). There was a positive correlation between uric acid levels and fibrosis severity $\left(\mathrm{R}^{2}=\right.$ $0.49, \mathrm{p}<0.05$ ) (fig. 2).

\section{OPN Expression}

OPN is a macrophage-adhesive protein that is expressed by tubules in CsA nephropathy and has been shown to correlate with macrophage infiltration, tubulointerstitial fibrosis, and renal function [16]. A significant increase was observed in rats treated with CsA, and the expression was reduced in both CsAALP- and CsABENZ-treated animals (table 2; fig. 3a, b).

Fig. 1. a Tubular atrophy was significantly increased in the cyclosporine group compared to control. Treatment with allopurinol or benzbromarone reduced tubular lesion to a greater extent than controls. b Interstitial fibrosis, analyzed by Sirius red staining $(\times 200)$, showed a similar pattern in the control group (c), stripped fibrosis pattern in CsA-treated animals (d), allopurinol group (e) and benzbromarone group (f) showing lower interstitial fibrosis. Arteriolar hyalinosis (g) and ischemic glomerulosclerosis (h) were increased in CsA-treated animals and limited by uric acidlowering agent treatment (CsAALP or CsABENZ). ${ }^{a} \mathrm{p}<0.05$ vs. control; ${ }^{\mathrm{b}} \mathrm{p}<0.05$ vs. CsA; ${ }^{\mathrm{c}} \mathrm{p}<0.05$ vs. CsAALP; ${ }^{\mathrm{d}} \mathrm{p}<0.05$ vs. CsABENZ. 

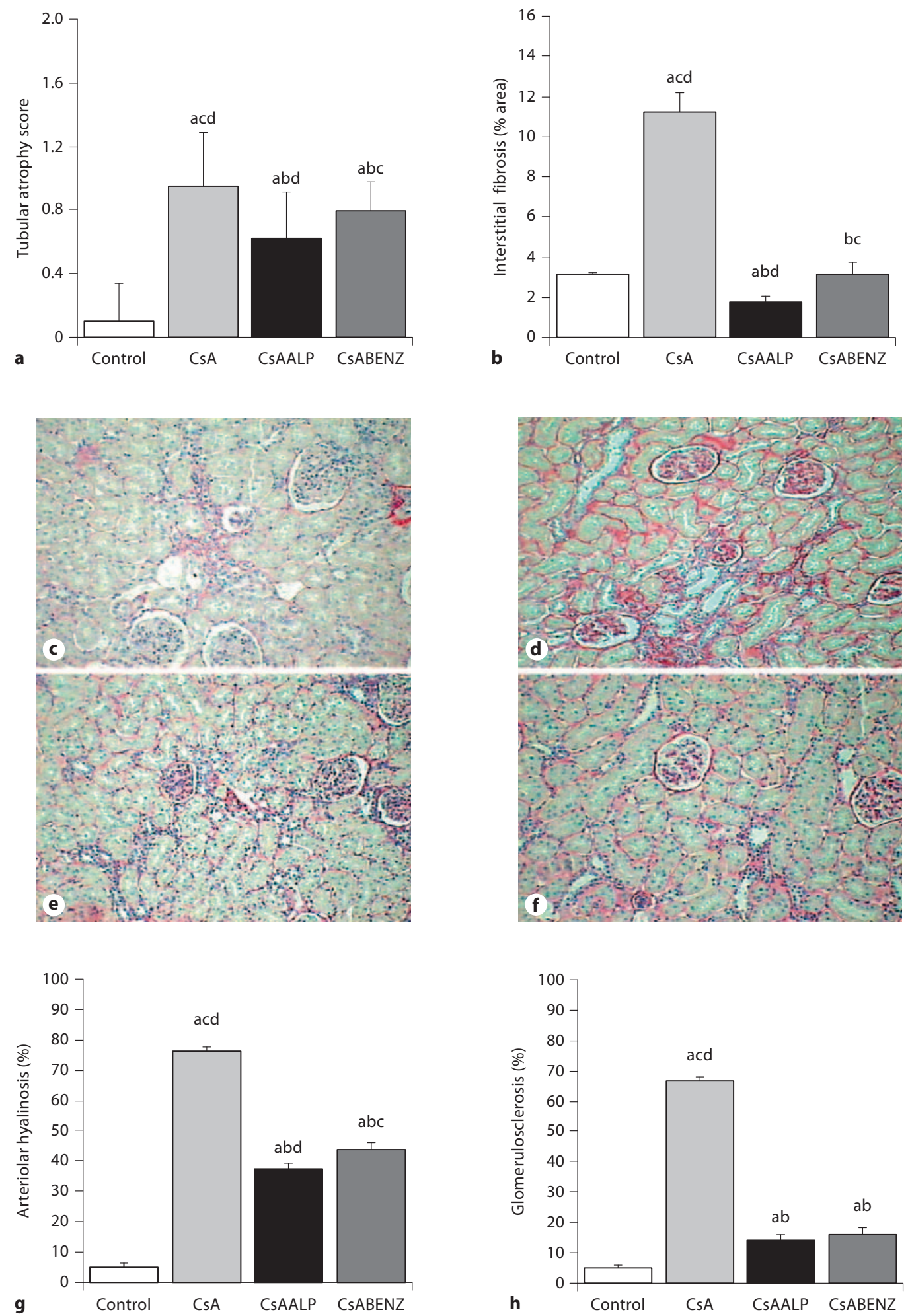
Table 2. Morphological data from study groups

\begin{tabular}{lcccc}
\hline & Control & CsA & CsAALP & CsABENZ \\
\hline Animals & 5 & 6 & 6 & 6 \\
Tubulointerstitial injury, PAS score & $0.026 \pm 0.01$ & $2.05 \pm 0.14^{\mathrm{a}, \mathrm{c}, \mathrm{d}}$ & $1.15 \pm 0.08^{\mathrm{a}, \mathrm{b}}$ & $1.51 \pm 0.11^{\mathrm{a}, \mathrm{b}}$ \\
Arteriolar hyalinosis, \% & $5.2 \pm 1.2$ & $76.1 \pm 1.29^{\mathrm{a}, \mathrm{c}, \mathrm{d}}$ & $37.3 \pm 1.3^{\mathrm{a}, \mathrm{b}, \mathrm{d}}$ & $43.7 \pm 1.7^{\mathrm{a}-\mathrm{c}}$ \\
Interstitial fibrosis, \% Sirius red positive & $3.14 \pm 0.05$ & $11.23 \pm 0.62^{\mathrm{a}, \mathrm{c}, \mathrm{d}}$ & $1.79 \pm 0.17^{\mathrm{a}, \mathrm{b}}$ & $3.16 \pm 0.53^{\mathrm{b}, \mathrm{c}}$ \\
OPN, \% area & $0.24 \pm 0.24$ & $2.09 \pm 0.34^{\mathrm{a}, \mathrm{c}, \mathrm{d}}$ & $0.63 \pm 0.29^{\mathrm{a}, \mathrm{b}}$ & $0.19 \pm 0.19^{\mathrm{b}}$ \\
Interstitial macrophages, ED1+ cell/mm $\mathrm{mm}^{2}$ & $1.78 \pm 0.14$ & $27.07 \pm 1.2^{\mathrm{a}, \mathrm{c}, \mathrm{d}}$ & $15.1 \pm 0.81^{\mathrm{a}, \mathrm{b}}$ & $16.4 \pm 3.4^{\mathrm{a}, \mathrm{b}}$ \\
Interstitial cell proliferation, PCNA+ cell & $1.42 \pm 0.06$ & $6.09 \pm 0.38^{\mathrm{a}, \mathrm{c}, \mathrm{d}}$ & $2.86 \pm 0.34^{\mathrm{a}, \mathrm{b}}$ & $3.31 \pm 0.39^{\mathrm{a}, \mathrm{b}}$ \\
Tubular cell proliferation, PCNA+ cell & $0.44 \pm 0.05$ & $2.29 \pm 0.24^{\mathrm{a}, \mathrm{c}, \mathrm{d}}$ & $1.29 \pm 0.23^{\mathrm{a}, \mathrm{b}}$ & $1.56 \pm 0.21^{\mathrm{a}, \mathrm{b}}$ \\
VEGF expression, \% area & $3.32 \pm 0.15$ & $1.24 \pm 0.10^{\mathrm{a}, \mathrm{c}, \mathrm{d}}$ & $2.65 \pm 0.25^{\mathrm{a}, \mathrm{b}}$ & $2.16 \pm 1.19^{\mathrm{a}, \mathrm{b}}$ \\
\hline
\end{tabular}

${ }^{\mathrm{a}} \mathrm{p}<0.05$ vs. control; ${ }^{\mathrm{b}} \mathrm{p}<0.05$ vs. CsA; ${ }^{\mathrm{c}} \mathrm{p}<0.05$ vs. CsAALP; ${ }^{\mathrm{d}} \mathrm{p}<0.05$ vs. CsABENZ.

\section{Macrophage Accumulation}

The increase in OPN expression in CsA-treated rats was associated with an accumulation of ED-1-positive macrophages in the interstitial space. Similar to the findings with OPN, kidneys from CsAALP and CsABENZ had lower macrophage infiltration compared to rats treated with CsA alone (table 2; fig. 3c, d). In addition, CsA-treated rats exhibited mild glomerular macrophage accumulation that was also reduced (albeit not significantly) in ALP- or BENZ-treated animals.

\section{Cell Proliferation}

Similar to the findings with OPN and ED-1, kidney biopsies from CsAALP and CsABENZ had lower cell proliferation compared to rats treated with CsA alone (table 2). In addition, CsA-treated rats exhibited mild glomerular cell proliferation, which was also reduced in allopurinol or benzbromarone-treated animals.

\section{VEGF Expression}

VEGF expression was reduced in both the medulla and cortex from the CsA-treated animals compared to controls. Treatment with allopurinol restored VEGF expression in both the cortex and medulla. However, CsABENZ-treated group maintained low expression of medullary VEGF expression, despite the restoration of cortical VEGF (table 2; fig. 3e, f).

\section{Discussion}

CsA nephropathy is a major complication of CsA therapy $[2,12]$, and is characterized by arteriolar hyalinosis and tubulointerstitial disease [13]. The pathogenesis is

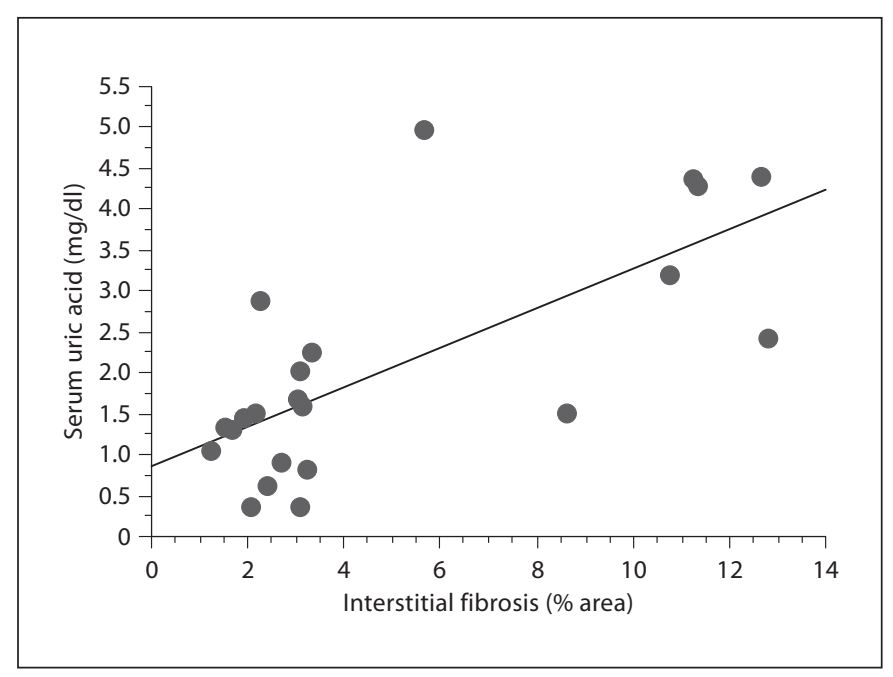

Fig. 2. Fibrosis correlates with uric acid levels. There was a positive correlation between uric acid levels and percent of interstitial fibrosis (Spearman correlation, $\mathrm{R}^{2}=0.49 ; \mathrm{p}<0.05$ ).

Fig. 3. a OPN expression was significantly increased in the CsA group compared to controls. Allopurinol therapy was associated with a reduction in OPN expression, but a strong effect was observed with benzbromarone treatment. b OPN staining in different groups. $\times 200$. c Interstitial macrophage infiltration (ED-1+ cells) significantly increased in the CsA group compared to control. Treatment with uric acid-lowering agents partially limited interstitial inflammation (d) and macrophage infiltration (ED1 staining) in different groups. $\times 200$. e VEGF expression was reduced in the cortex and medulla in CsA-treated animals, compared to control. Treatment with uric acid-lowering agents partially restored VEGF expression. $\mathbf{f}$ VEGF staining in different groups. $\times 200 .{ }^{\mathrm{a}} \mathrm{p}<0.05$ vs. control; ${ }^{\mathrm{b}} \mathrm{p}<0.05$ vs. CsA; ${ }^{\mathrm{c}} \mathrm{p}<0.05$ vs. CsAALP; ${ }^{\mathrm{d}} \mathrm{p}<0.05$ vs. CsABENZ. 


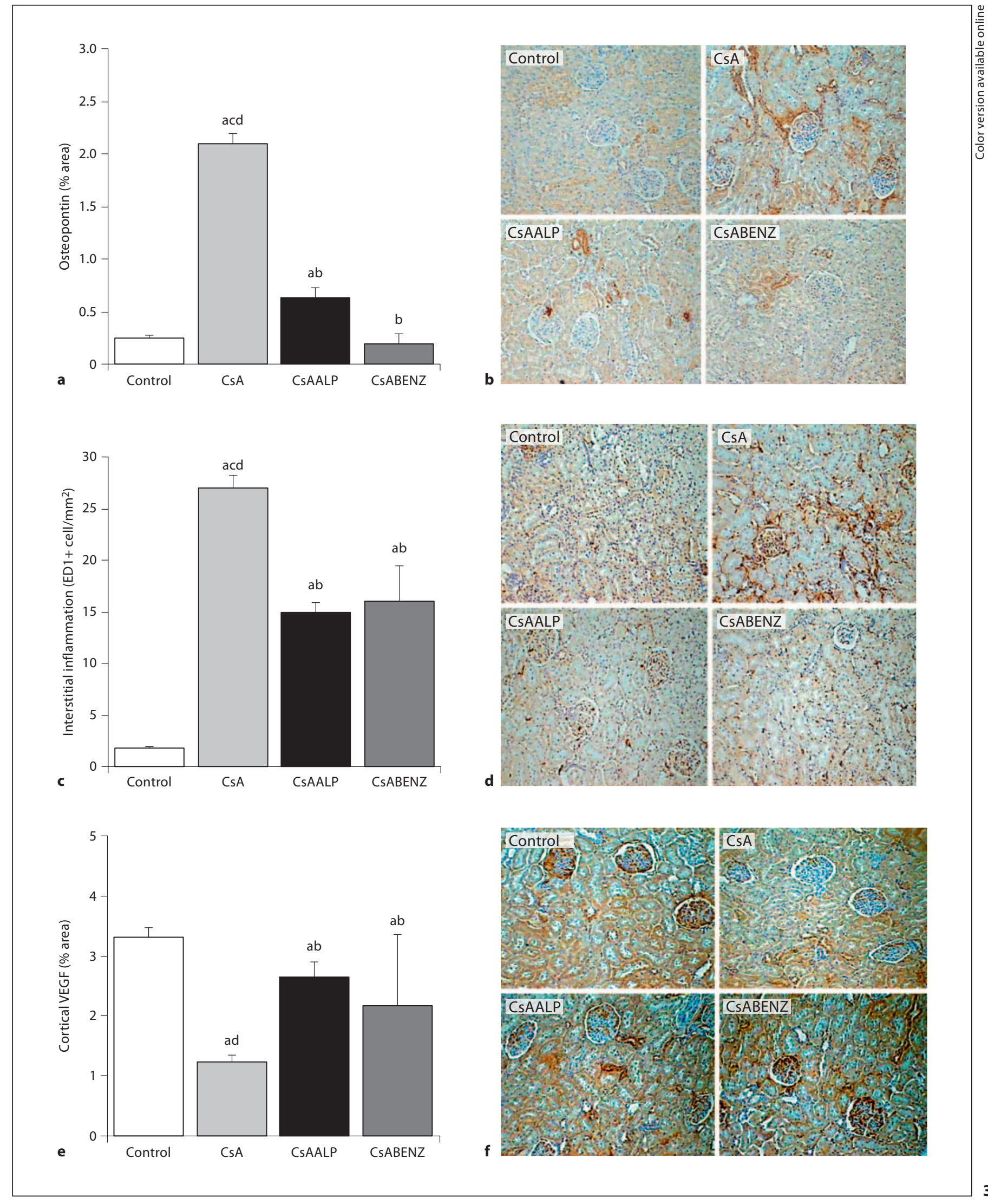


considered secondary to intense renal vasoconstriction induced by angiotensin II and other vasoactive substances $[1,14,15]$.

CsA use is also associated with the development of hyperuricemia secondary to a reduction in uric acid excretion $[26,27]$. Although the risk of hyperuricemia in patients on CsA has generally been considered only to be gout [8], it is of interest that there has been a longstanding controversy on the role of hyperuricemia in mediating tubulointerstitial diseases. Previous experimental studies have shown that uric acid causes a mild interstitial renal disease with an ischemic pattern that is mediated by preglomerular vasoconstriction and afferent arteriolar vasculopathy $[19,28]$.

The cyclosporine nephropathy model is also associated with a significant increase in serum uric acid with a reduction in fractional urate excretion. These findings are similar to those observed in humans treated with CsA and document the clinical relevance of this model [17]. Treatment with allopurinol or benzbromarone reduces serum uric acid levels by decreasing urate production or by increasing uric acid excretion, respectively, as demonstrated by the maintenance of serum uric acid within normal levels in the CsAALP and CsABENZ groups.

The major finding in this study was that normalization of uric acid levels reduced the tubulointerstitial disease and arteriolar hyalinosis induced by cyclosporine. Tubulointerstitial injury was significantly lower in rats treated with CsAALP or CsABENZ compared to the CsA group, including measurements of OPN (a sensitive marker of tubular injury), interstitial macrophage accumulation, interstitial collagen deposition and cell proliferation. The frequency of arterioles with arteriolopathy was also significantly reduced in CsAALP and CsABENZ animals compared to CsA-treated rats alone.

The mechanism by which hyperuricemia exacerbates renal injury does not involve intrarenal crystal deposition. Previous studies suggested that hyperuricemia causes an ischemic pattern of interstitial disease, similar to the CsA model [19], and some clinical studies have shown that uric acid levels correlate with the development or worsening of renal disease [29-31]. Concomitant treatment with allopurinol or benzbromarone prevented the ischemic injury, as shown by a lower incidence of arteriolopathy with maintained expression of VEGF in the renal cortex. Interestingly, allopurinol treatment also was associated with preservation of VEGF in the medulla in contrast to CsABENZ-treated rats. For some markers, especially for interstitial fibrosis and vasculopathy, allopurinol treatment was associated with a superior protective effect compared to benzbromarone. Allopurinol has also been thought to block oxidant generation, since xanthine oxidase will generate both uric acid and superoxide anion from xanthine. However, allopurinol is a purine analog, and while it prevents uric acid formation it continues to generate superoxide in association with the production of alloxanthine [32]. Hence, the primary effect of allopurinol is likely by blocking uric acid generation. Indeed, the observation that benzbromarone also caused a marked improvement in renal histology further suggests that uric acid plays an important role in this model.

Previous studies have suggested that allopurinol treatment can reduce the renal vasoconstriction associated with experimental CsA toxicity [33]. In addition, Neal et al. [34] reported that allopurinol treatment can improve renal function in liver transplant recipients receiving CsA therapy. In neither study was renal histology examined, nor were the changes attributed to uric acid. However, the data in the current paper suggest that the mechanism by which allopurinol is likely providing benefit is by its ability to lower uric acid. As the effect of allopurinol treatment can be attributed, at least in part, to an antioxidant effect of the drug, we tested benzbromarone, a uricosuric agent with a different mode of action from allopurinol, as a control for uric acid reduction effects. The similarity of findings in both treated groups (allopurinol and benzbromarone) suggests that the protective effect could be attributed to the normalization of uric acid levels.

In conclusion, this study suggests that treatment of hyperuricemia may limit the severity of CsA-induced nephropathy. The comparable results in both allopurinol and benzbromarone groups suggest that this effect can be attributed more to uric acid normalization than a possible antioxidant effect of allopurinol.

\section{Acknowledgements}

R.J.J. was supported in part by NIH grants HL-68607, DK52121, and HL-79352. F.C.M. received a fellowship grant from Fundação de Amparo à Pesquisa do Estado de São Paulo - FAPESP (04/05026-9 and 07/055084-3). 


\section{References}

1 Bennett WM, De Mattos A, Meyer MM, Andoh TF, Barry JM: Chronic cyclosporine nephropathy. The Achille's heel of immunosuppressive therapy. Kidney Int 1996;50: 1089-1100.

$\checkmark 2$ Myers BD, Newton L: Cyclosporine induced chronic nephropathy: an obliterative microvascular renal injury. J Am Soc Nephrol 1991;2(suppl 1):S45-S52.

$\checkmark 3$ Chapman JR, Harding NGL, Griffiths D, Morris PJ: Reversibility of cyclosporine nephrotoxicity after three months treatment. Lancet 1985;19:128-130.

4 Gores PF, Fryd DS, Sutherland DER, Najarian JS, Simmons RL: Hyperuricemia after renal transplantation. Am J Surg 1988;156: 397-400.

5 Kahl LE, Thompson ME, Griffith BP: Gout in the heart transplant recipient: Physiological puzzle and therapeutic challenge. Am J Med 1989;87:289-294.

6 Najarian JS, Fryd DS, Strand M: A single institution, randomized, prospective trial of cyclosporine versus azathioprine-antilymphocyte globulin for immunosuppression in renal allograft recipients. Ann Surg 1985; 201:142-157.

7 Sutherland DER, Fryd DS, Strand MH: Minnesota randomized prospective trial of cyclosporine versus azathioprine-antilymphocyte globulin for immunosuppression in renal allograft recipients. Am J Kidney Dis 1985;5:318-327.

$\checkmark 8$ West C, Carpenter BJ, Hakala TR: The incidence of gout in renal transplant recipients. Am J Kidney 1987;10:369-372.

-9 Zurcher RM, Bock HÁ, Thiel G: Hyperuricemia in cyclosporine treated patients: a GRF related effect. Nephrol Dial Transplant 1996;11:153-158.

10 Laine J, Holmberg C: Mechanisms of hyperuricemia in cyclosporine-treated renal transplanted children. Nephron 1996;74: 318-323.

-11 Marcen R, Gallego N, Orofino L, Gamez C, Estepa MR, Sabater J, Teruel JL, Ortuno J: Impairment of tubular secretion of urate in renal transplant patients on cyclosporine. Nephron 1995;70:307-317.

12 Myers B: Cyclosporine nephrotoxicity. Kidney Int 1986;30:964-974.
13 Mihatsch MJ, Thiel G, Ryffel B: Histopathology of cyclosporine nephrotoxicity. Transplant Proc 1988;20(suppl 3):759-771.

14 Bennett WM, Burdmann EA, Andoh T, Houghton DC, Lindsey J, Elzinga LW: Nephrotoxicity of immunosuppressive drugs. Nephrol Dial Transplant 1994;9(suppl 4): 141-145.

-15 Burdmann EA, Andoh T, Nast CC, Evan A, Connors BA, Coffman TN, Lindslay J, Bennett WN: Prevention of experimental cyclosporine induced interstitial fibrosis by losartan and enalapril. Am J Physiol 1995; 269:F491-F499.

16 Pichler RH, Franceschini N, Young BA Hugo C, Andoh TF, Burdmann EA, Shankland SJ, Alpers CE, Bennett WN, Couser WG, et al: Pathogenesis of cyclosporine nephropathy. Role of angiotensin II and osteopontin. J Am Soc Nephrol 1995;6:1186-1196.

$>17$ Mazzali M, Kim YG, Suga S, Gordon KL, Kang DH, Jefferson JÁ, Hughes J, Kivlighn SD, Lan HY, Johnson RJ: Hyperuricemia exacerbates chronic cyclosporine nephropathy. Transplantation 2001;71:900-905.

18 Kang DH, Nakagawa T, Feng L, Watanabe S, Han L, Mazzali M, Truong L, Harris R, Johnson RJ: A role for uric acid in the progression of renal disease. J Am Soc Nephrol 2002;13: 2888-2897.

19 Mazzali M, Hughes J, Kim YG, Jefferson JÁ, Kang DH, Gordon KL, Lan HY, Kivlighn SD, Johnson RJ: Elevated uric acid increases blood pressure in the rat by a crystal independent mechanism. Hypertension 2001;38: 1101-1106.

20 Khosla UM, Zharikov S, Finch JL, Nakagawa T, Roncal C, MuW, Krotova K, Block ER, Prabhakar S, Johnson RJ: Hyperuricemia induces endothelial dysfunction. Kidney Int 2005;67:1739-1742.

21 Sanchez-Lozada LG, Tapia E, Avila Casado C, Soto V, Franco M, Santamaria J, Nakagawa T, Rodriguez-Iturbe B, Johnson RJ, Herrera-Acosta J: Mild hyperuricemia induces glomerular hypertension in normal rats. Am J Physiol Renal Physiol 2002;283:F1105F1110.

-22 Mazzali M, Kanellis J, Han L, Feng L, Xia YY, Chen Q, Kang DH, Gordon KL, Watanabe S, Nakagawa T, Lan HY, Johnson RJ: Hyperuricemia induces a primary renal arteriolopathy in the rat by a blood pressure independent mechanism. Am J Physiol Renal Physiol 2002;282:F991-F997.
23 Kang DH, Park SK, Lee IK, Johnson RJ: Uric acid induced $\mathrm{C}$ reactive protein (CRP) expression: implication on cell proliferation and nitric oxide production of human vascular cells. J Am Soc Nephrol 2005;16:35533562.

24 Bennet WM: Drug interactions and consequences of sodium restriction. Am J Clin Nutr 1997;65(suppl 2):678S-681S.

25 Giachelli CM, Pichler R, Lombardi D, Denhardt DT, Alpers CE, Schwartz SM, Johnson RJ: Osteopontin expression in angiotensin II induced tubulointerstitial nephritis. Kidney Int 1994;45:515-524.

26 Hoyer PF, lee IK, Oemar BS, Krohn HP, Offner $\mathrm{G}$, Brodhel J: Renal handling of uric acid under cyclosporine A treatment. Pediatr Nephrol 1988;2:18-21.

27 Mazzali M: Uric acid and transplantation. Semin Nephrol 2005;25:50-55.

28 Sanchez Lozada LG, Tapia E, RodriguezIturbe B, Johnson RJ, Herrera-Acosta J: Hemodynamics of hyperuricemia. Semin Nephrol 2005;25:19-24.

-29 Iseki K, Ikemyia Y, Inoue T, Iseki C, Kinjo K, Takishita S: Significance of hyperuricemia as a risk factor for developing ESRD in a screened cohort. Am J Kidney Dis 2004;44: 642-650.

-30 Ruilope LM, Garcia-Puig J: Hyperuricemia and renal function. Curr Hypertens Rep 2001;3:197-202.

31 Short RA, Johnson RJ, Tuttle KR: Uric acid, microalbuminuria and cardiovascular events in high risk patients. Am J Nephrol 2005;25:36-44.

-32 Miyamoto Y, Akaike T, Youshida M, Goto S, Horie $\mathrm{H}$, Maeda $\mathrm{H}$ : Potentiation of nitric oxide mediated vasorelaxation by xanthine oxidase inhibitors. Proc Soc Exp Biol Med 1996;211:366-373.

>33 Assis SM, Monteiro JL, Seguro AC: L-arginine and allopurinol protects against cyclosporine nephrotoxicity. Transplantation 1997;63:1070-1073

34 Neal DA, Tom BD, Gimson AE, et al: Hyperuricemia, gout, and renal function after liver transplantation. Transplantation 2001;72: 1689-1691.
Uric Acid-Lowering Agents Limit Experimental Cyclosporine Nephropathy
Nephron Exp Nephrol 2012;120:e12-e19 